\title{
GPON Unbundling for Multioperator Access
}

\author{
David Carmona Torondel ${ }^{1,2}$, Josep Prat Gomà ${ }^{1}, M^{a}$ Pilar Sánchez Marco ${ }^{2}$. \\ ${ }^{1}$ Grupo de Comunicaciones Ópticas. Departamento de Teoría de la Señal y Comunicaciones. \\ Escuela Técnica Superior de Ingeniería de Telecomunicación de Barcelona. \\ Universitat Politècnica de Catalunya. \\ ${ }^{2}$ Comisión del Mercado de las Telecomunicaciones.
}

\section{OUTLINE / MOTIVATION}

Nowadays, incumbent operators are deploying GPON FTTH access network over substantial part of the countries in Europe, in a Point-to-Multipoint architecture (P2MP). This architecture is characterized by a shared fiber from the Central Office (C.O.) to a certain location where, by means of splitters, individual fibers carry the signal to/from every user. It is preferable for an open market situation, where the competition in prices and services is desirable and also enforced by local governments and administrations, to have different entry options to the market for the many alternative operators (entrants) which may come up and compete with the incumbent. For that reason, this study aims at considering different unbundling options for the Local Loop Unbundling (LLU) in order to provide multioperator access and consider the economical impact for the entrants to deploy such alternatives.

The scope of this study primarily covers remedies to be imposed upon operators designated with Significant Market Power (SMP) on the basis of a market analysis procedure carried out under Article 16 of Directive 2002/21/EC [EUC02a]. However, where it is justified on the grounds that duplication of infrastructure is economically inefficient or physically impracticable, the regulator may also impose obligations of reciprocal sharing of facilities on undertakings operating an electronic communications network in accordance with Article 12 of that Directive which would be appropriate to overcome bottlenecks in the civil engineering infrastructure and terminating segments.

This work deals with the following issues:

- $\quad$ Alternatives for LLU: although there are several methods, the next three have been considered as they are the most feasible in terms of cost, scalability and upgradeability, in the number of clients and operators. [ALC10a] [FCE11c] [ISD09a] [MAS09a] [ITU08a] [WKC10a]

o Move the Splitters Back.

o Replicate the Access Network.

o Upgrading to WDM technologies.

- $\quad$ Results / Comparison: both absolute and incremental costs, starting from a P2MP deployment for the different unbundling strategies.

Alternative operators, some of whom have already deployed their own networks to connect to the unbundled copper loop of the SMP operator, need to be provided with appropriate access products in order to continue to compete in an NGA context. For FTTH these may consist of access to civil engineering infrastructure, to the terminating segment, to the unbundled fiber loop (including dark fiber) or of wholesale broadband access, as the case may be. This work, although aiming to be general, takes the relevant data from the Spanish FTTH case.

Where remedies imposed on Market 4 lead to effective competition in the corresponding downstream market, in the whole market or in certain geographic areas, other remedies could be withdrawn in the market or areas concerned. Such withdrawal would be indicated, for instance, if the successful imposition of physical access remedies were to render additional bitstream remedies redundant. Moreover, in exceptional circumstances, the regulator could refrain from imposing unbundled access to the fiber loop in geographic areas where the presence of several alternative infrastructures, such as FTTH networks, in combination with competitive access offers on the basis of unbundling, is likely to result in effective competition on the downstream level. [EUC10c] 


\section{ALTERNATIVES FOR LOCAL LOOP UNBUNDLING}

In a Fiber to the Home context duplication of the terminating segment of the fiber loop will normally be costly and inefficient. To allow for sustainable infrastructure competition, it is therefore necessary that access be provided to the terminating segment of the fiber infrastructure deployed by the SMP operator. To ensure efficient entry, it is important that access is granted at a level in the network of the SMP operator which enables entrants to achieve minimum efficient scale to support effective and sustainable competition. [EUC10c]

Three methods have been analyzed as they are considered the most feasible. The departure point is the P2MP network already deployed by the incumbent [Fig. 1], where in addition to the single fiber from the C.O. to the splitter premises the operator has deployed some spare fibers to use in later network upgrades. These fibers remain unconnected and can be used to reduce costs significantly.

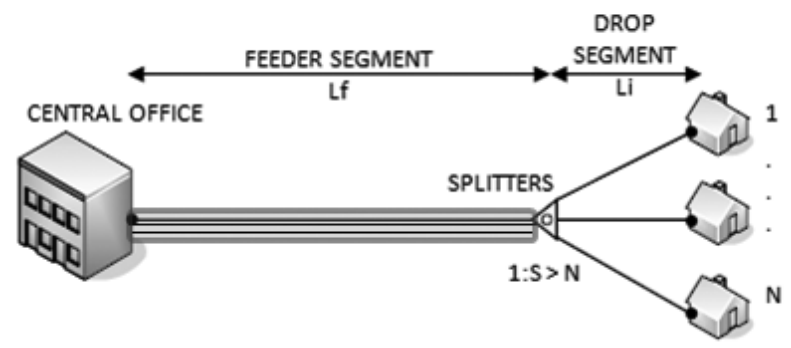

Fig. 1 - P2MP departure point deployment diagram.

\section{Move Splitters Back}

The goal of this approach is to modify the architecture of the current deployment to get a P2P-like architecture, where each customer has a single dedicated fiber.

1. The first step is to remove the splitters and put them back as close to the C.O. as possible:

2. Then, some extra fibers have to be deployed for the feeder segment, to connect the splitters to the users' fibers and perform some fiber fusions.
3. Finally, the unbundling can take place at the C.O. where an entrant operator has to deploy its own infrastructure to get there.

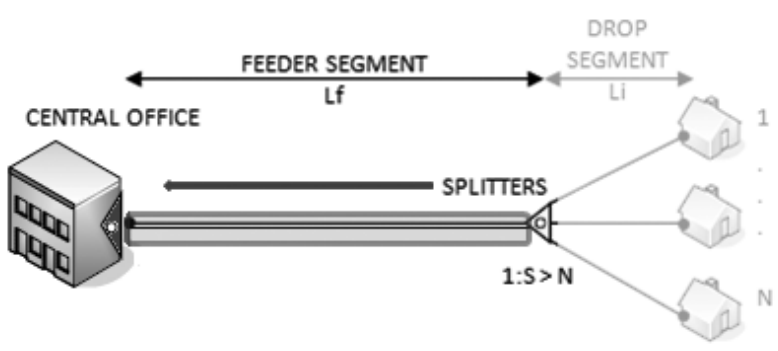

Fig. 2 - Move splitters back.

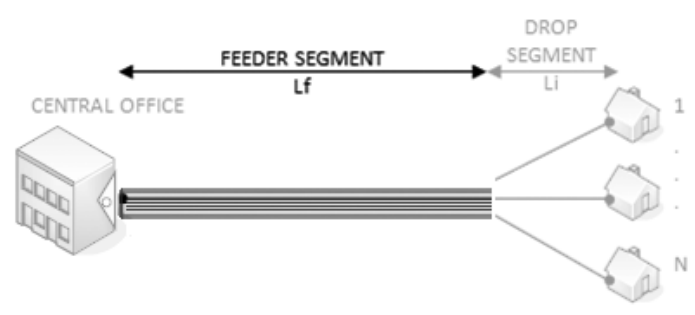

Fig. 3 - Deploy extra fibers.

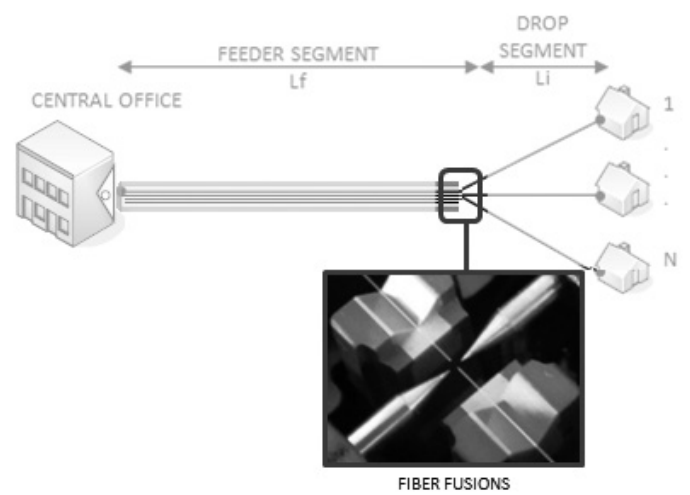

Fig. 4 - Fiber fusions at former splitters location.

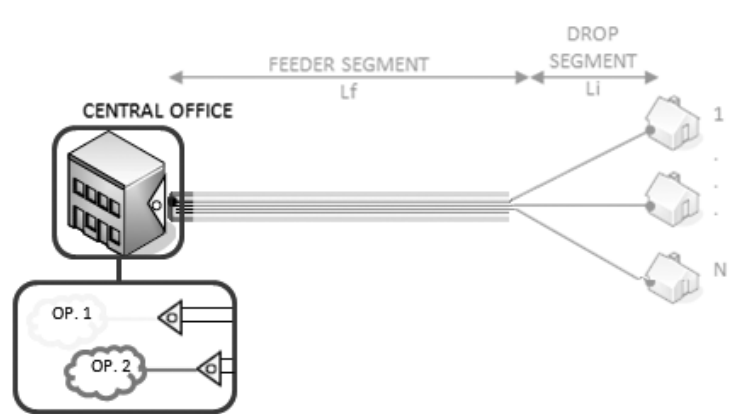

Fig. 5 - Move splitters back: entrant operator in incumbent's C.O. 


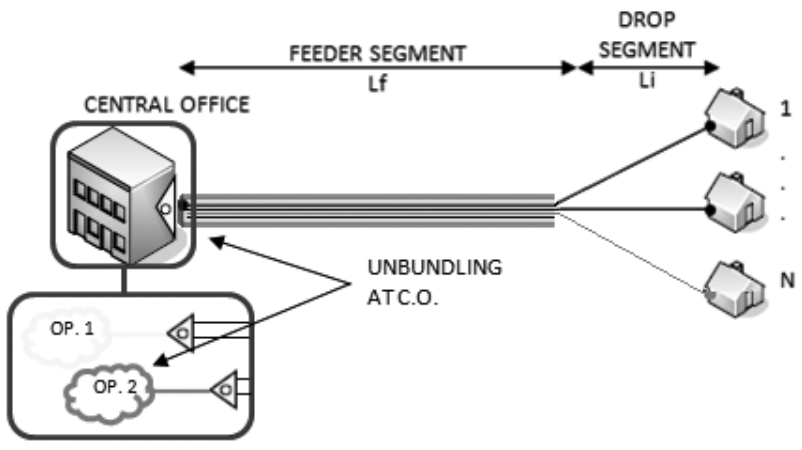

Fig. 6-Move splitters back: unbundling at C.O.

The total costs of this upgrade are the related to:

- $\quad$ extra fiber deployment, which is calculated as the $70 \%$ of a normal fiber deployment due to the spare fibers. This $\%$ may vary in a great range, from $10 \%$ to $120 \%$, according to the city structure. $70 \%$ has been considered the usual value for the models described in this study. [FCE11c] [ISD09a] [MAS09a] [ITU08a] [WKC10a]

- trenching for the feeder segment, where necessary.

\section{- fiber fusions.}

- maybe some extra space in the C.O. has to be considered to place the splitters.

\section{Replicate Access Network}

A different approach aims at deploying a second access network, particularly the drop segment, to use by the entrant operator. The entrant arrives to the splitters location with its own infrastructure. In this configuration, either at least a couple of fibers connect every user with the splitter premises or the entrant operator changes the user's connections to its own splitters.

1. The entrant operator arrives to the incumbent's splitters location with its own infrastructure (feeder segment). Some extra splitters have to be deployed in order to connect the drop segment fibers with the customers. There's the issue when there's not enough space for such splitters so additional digging has to be done to house this equipment.

2. In some cases, extra fiber needs to be deployed between the splitters and the customer premises.
3. The unbundling can be done then at the splitters location.

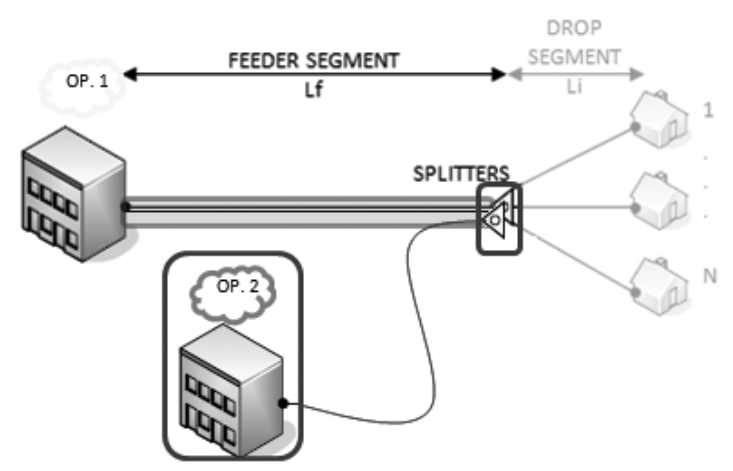

Fig. 7 -Entrant operator deploys fiber to the incumbent splitters location and extra splitters.

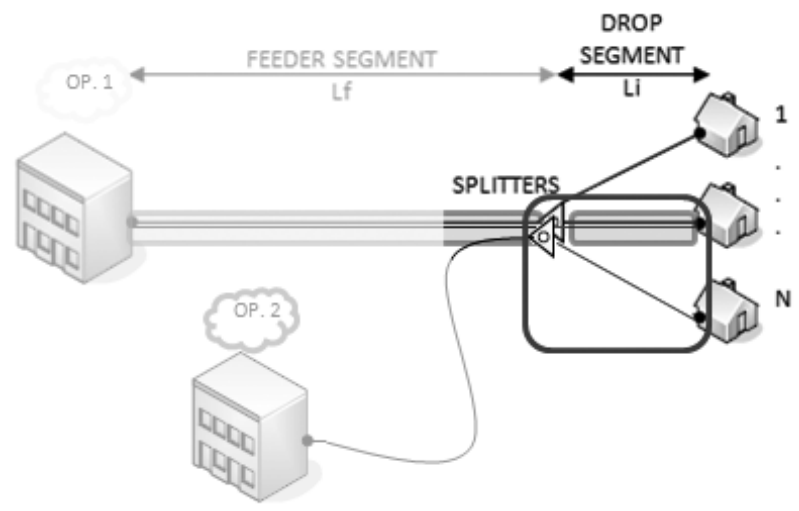

Fig. 8 - Entrant deploys alternative fiber to the customer or changes the fiber connection at the splitters location.

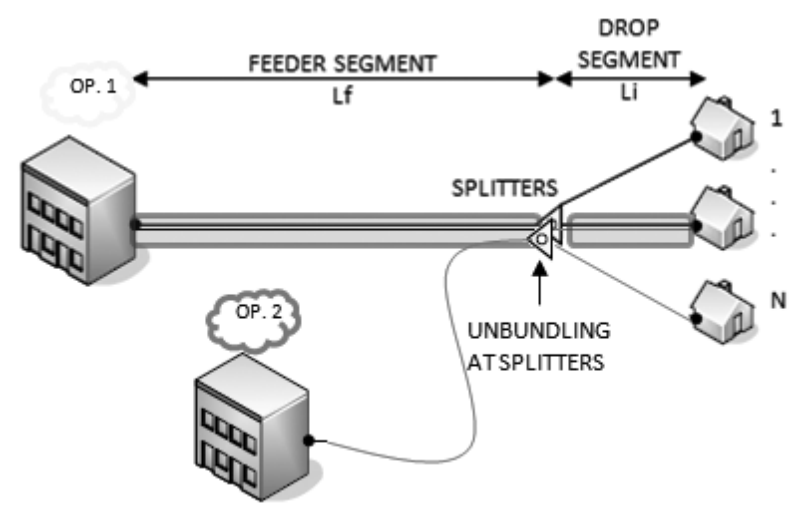

Fig. 9 -Replicate access network: unbundling at splitters

The total costs of this upgrade are the related to:

- $\quad$ extra fiber deployment, which is calculated as the $70 \%$ of a normal fiber deployment due to the spare fibers and changing of connections. Note that when deploying fibers a common strategy is to deploy se- 
veral 128 fiber cables to fill the whole trench. The unused fibers remain unconnected (dark fibers) and ready to be used for new deployments or future network upgrades.

- trenching for the feeder segment.

- $\quad$ extra splitters.

- maybe some extra space in the splitters location has to be considered to place the splitters.

\section{WDM PON}

The last alternative considered is an upgrade to WDM PON architecture. In this network, every user has a wavelength assigned. The changes needed occur in the C.O. where the current OLTs have to be changed for ones that support WDM technologies, and in the splitters location, where all the splitters have to be substituted by WDM filters, one for each user. Also, at the C.P.E., different options are available (light sources at $\mathrm{ONU})$.

1. Old GPON equipment has to be substituted by WDM PON equipment: WDM OLT in the Central Office, replace splitters with WDM multiplexers (AWG) 1:32 and install filters and new light source at the C.P.E.

2. The entrant operator has to install its own infrastructure in the Central Office.

3. Finally, with both the incumbent and the entrant operating different wavelengths, the unbundling takes place at the C.O.

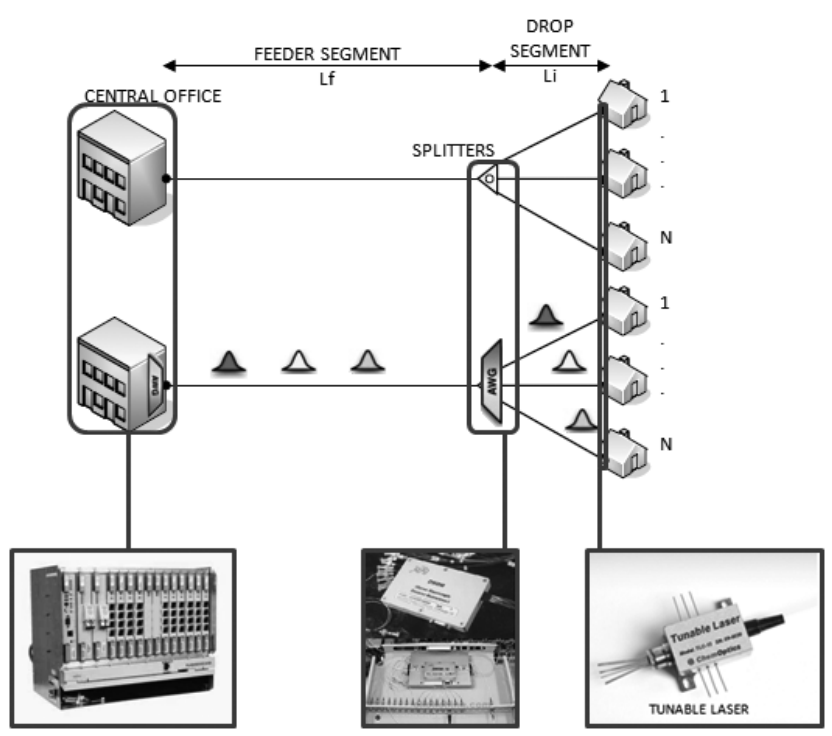

Fig. 10-WDM PON equipment upgrading.

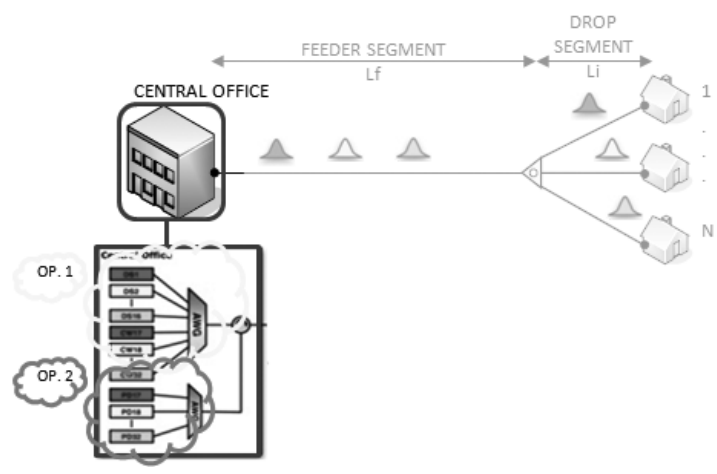

Fig. 11 - WDM PON: entrant operator in incumbent's C.O.

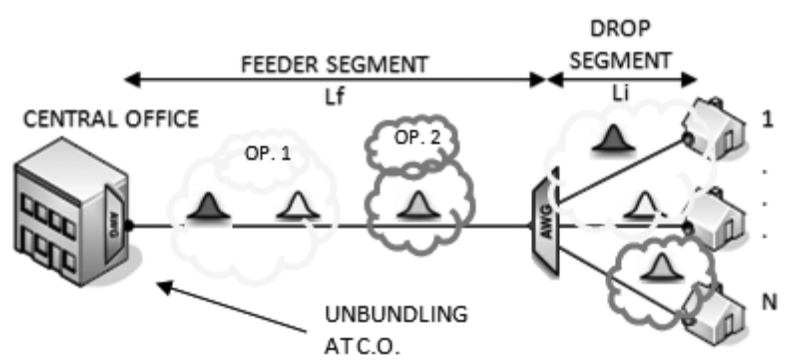

Fig. 12 - WDM PON: unbundling at C.O.

The total costs of this upgrade are the related to:

- C.O. changing the OLT equipment to support WDM technologies.

- $\quad$ Substituting the splitters by WDM filters.

- $\quad$ Light sources at ONU

o Laser at $\lambda \mathrm{i}$ (one different lambda for user)

o Tunable laser

o RSOA

\section{COSTS CALCULATION}

Initial deployments: P2P vs P2M

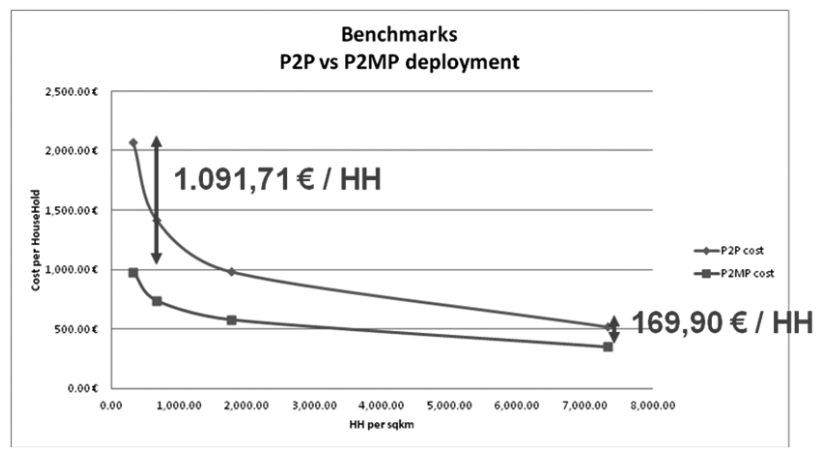

Graph 1 -Benchmarks: P2P vs P2MP deployment costs comparison. 
[Graph 1] shows the departure point for this study, where two architectures, $\mathrm{P} 2 \mathrm{MP}$ and $\mathrm{P} 2 \mathrm{P}$ are compared in terms of deployment cost per household in different household density areas. P2P deployments have larger costs mainly due to the amount of fiber needed, as every customer has its own fiber from the C.O. to the CPE. As expected, for lower density areas the cost increase and also the difference in cost between both architectures is greater. The trend is to converge to a stable and low cost for both architectures as the density increases.

As this is the start point, it is expected for all the alternatives considered to fall in between these cost curves, so it is easy to compare which of the alternatives is more cost-effective.

\section{Unbundling alternatives}

\section{1.- Move Splitters Back}

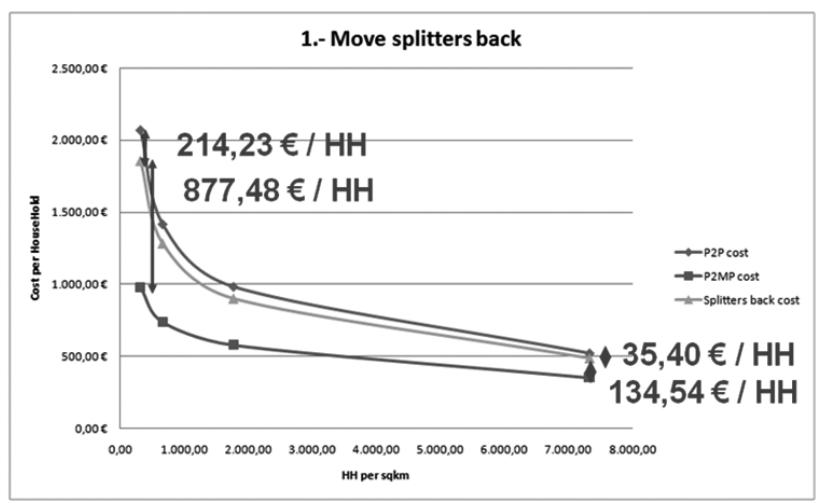

Graph 2 - Cost comparison between benchmark and "move splitters back" alternative.

When moving the splitters back, the costs obtained are very high, almost reaching the P2P curve. The more spare fibers used, the low the cost curve becomes, so the costs for the alternative decrease, as shown in [Graph 2]. The costs reflected in the previous graphs are related to not using any spare fiber. Again the trend is to reach some equilibrium point for higher household density areas.

\section{2.- Replicate Access Network}

The second alternative turns to be less costly than the first and falls more or less in the middle of the base deployments considered (P2P and P2MP). [Gra- ph 3] shows the case for a single entrant deploying its own network.

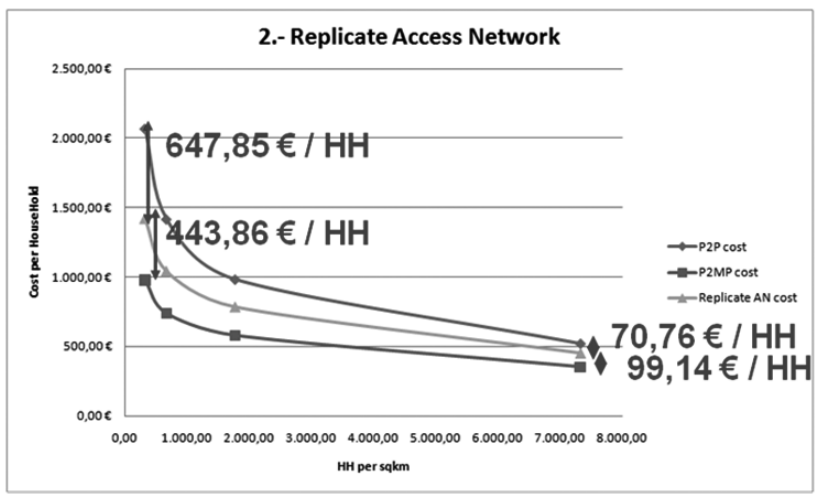

Graph 3-Cost comparison between benchmark and "replicate access network" alternative.

\section{Replicate Access Network for multiple operators}

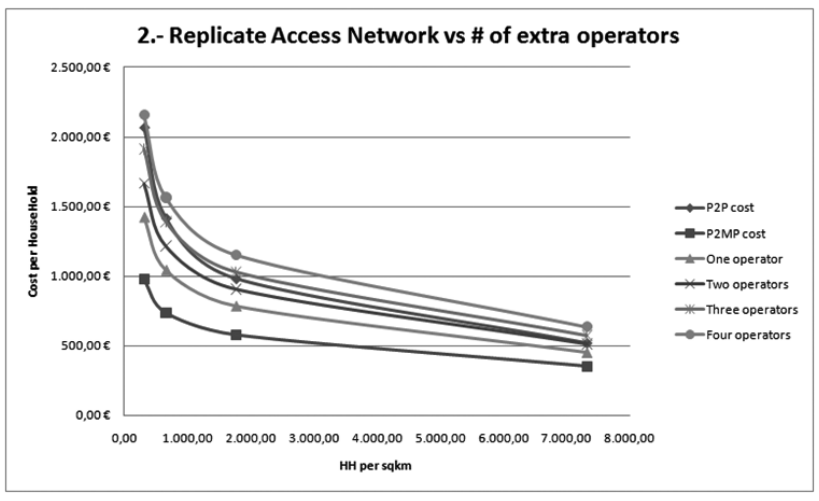

Graph 4 - Cost comparison between benchmark and extra entrant operators replicating the access network.

For many entrants, as shown in [Graph 4], the related costs increase, taking into account that the trenching costs are shared and every operator assumes the fiber deployment costs. For one and two extra operators (entrants) the costs are reasonable and lower than the P2P case.

When a third operator deploys its network the costs reach the $\mathrm{P} 2 \mathrm{P}$ case and go over it for a certain household density. The fourth operator is unviable, as its costs overcome the P2P case. Normally there are not more than two entrants willing to deploy their network in a city, so this strategy is fully acceptable.

These costs have been calculated for individual entrants. When two or more operators deploy their infrastructure simultaneously, sharing expenses leads to a decrease in final cost per operator. 


\section{3.- WDM PON}

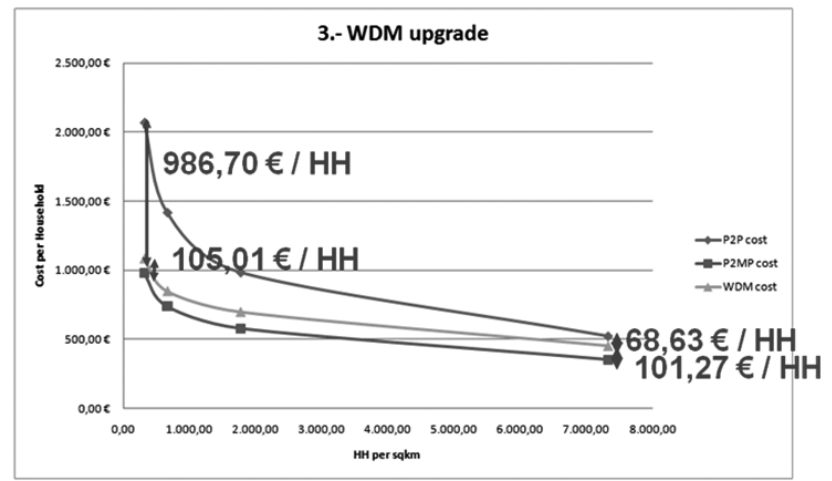

Graph 5-Cost comparison between benchmark and "WDM upgrade” alternative.

As the main costs for WDM upgrade are the related to the OLT equipment and filters for the users, this strategy has the lower costs, compared to the previous ones. [Graph 5]

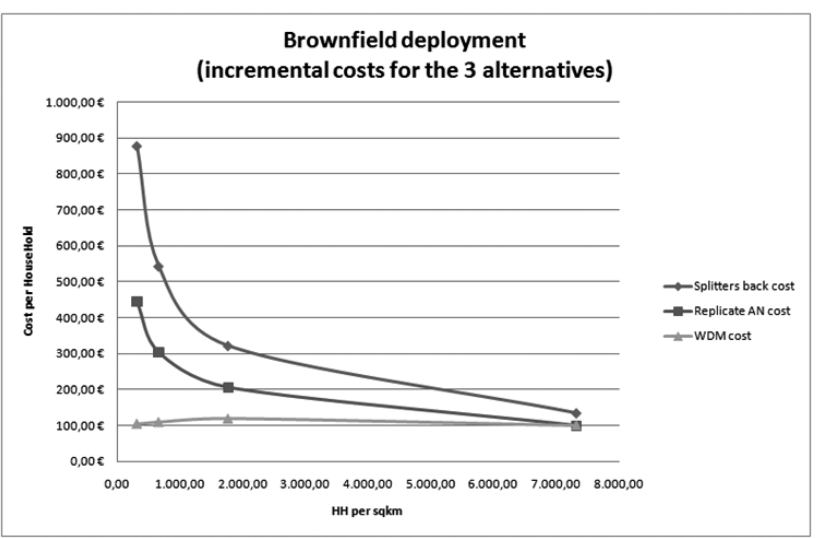

Graph 6-Cost comparison for the three alternatives considered.

[Graph 6] shows the incremental cost for each alternative, not taking into account the previous network deployment. As we have seen so far, the first alternative, taking the splitters back, is the costly one, with costs decreasing as the household density increases. The second one, replicating the access network (shown here for one extra operator) is the intermediate one in terms of cost, also decreasing with the household density. And the WDM upgrade is the least costly of the three. As expected, all three tend to an equilibrium point as the household density increase.

\section{CONCLUSIONS}

Despite WDM equipment is the most expensive, deploying WDM networks is a low-cost strategy to perform local loop unbundling while upgrading the network for the new era where high bandwidths are necessary for satisfying customers' demand. In areas with high population density WDM techniques are the most suitable for entrant operators to access the incumbent's network and provide service.

\section{REFERENCES}

[ALC10a] FTTH network economics - Key parameters impacting technology decisions.

[BOE11a] Real Decreto 346-2011, de 11 de marzo.

[EUC02a] Directive 2002-21-EC on a common regulatory framework for electronic communications networks and services (Framework Directive).

[EUC10c] Commission Recommendation on regulated access to Next Generation Access Networks (NGA).

[FCE10a] FTT(H,B) Panorama European Union (36) at December 2010.

[FCE11a] FTTH Council Europe Annual Report April 2010 - April 2011.

[FCE11b] European FTTH Forecast, 2010-2015.

[FCE11c] FTTH Business Guide 2011.

[FCE11d] FTTH Handbook 2011.

[ISD09a] Informe final sobre los resultados del modelo de despliegue de redes FTTH-GPON en España.

[ITU03a] Redes ópticas pasivas con capacidad de gigabits: Especificación de la capa dependiente de los medios físicos - G.984.2.

[ITU05a] Sistemas de acceso óptico de banda ancha basados en redes ópticas pasivas - G.983.1. 
[ITU08a] Gigabit-capable passive optical networks (GPON) - General characteristics - G.984.1.

[ITU08b] Whitepaper ITU-T G 657 Bend-optimised Single mode fiber.

[MAS09a] Competitive models in GPON.

[SIG07A] Techno-Economics of Residential Broadband Deployment.

[WKC10a] Architectures and competitive models in fiber networks - report.

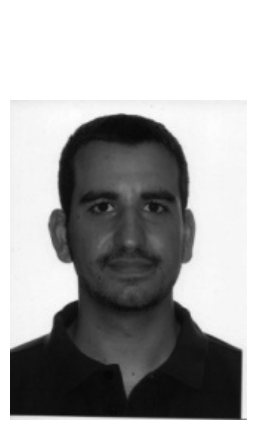

\section{AUTHORS}

David Carmona Torondel (david. carmona@ieee.org) received his degree in Telecommunication Engineering from the Universitat Politècnica de Catalunya (UPC) and carried out his end-degree project both in the Spanish telecommunications regulator "Comisión del Mercado de las Telecomunicaciones" (CMT) and in the Optical Communications Group of the Signal Theory and Communications Department of the UPC: a Techno-economical study of solutions for multioperator access to the local loop in next generation access networks (NGA). He has published 4 papers regarding his end-degree project in several international congresses related to optical communications. He has obtained a mention of honor and has been awarded with the Càtedra CMT-UPC's best end-degree project prize. He is an active member of the IEEE and the IEEE Communications Society and the former chairman of the IEEE Student Branch Barcelona. He is currently working as a systems integration \& technology consultant for an important multinational company.

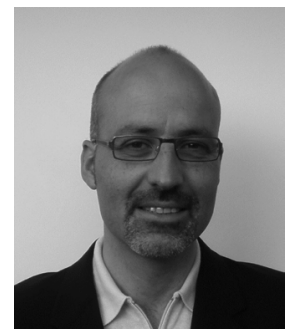

Prof. Josep Prat (jprat@tsc.upc. edu) received the $\mathrm{Ph} . \mathrm{D}$. degree from the Universitat Politècnica de Catalunya (UPC), Barcelona, in 1995. He is full professor in the Optical Communications Group of the Signal Theory and Communications Department of the UPC. He has mainly investigated on broadband optical communications with emphasis on high bit-rate optical systems, access networks and WDM transmission design and impairment control. He led the FP7 European project SARDANA ("Scalable Advanced Ring-based passive Dense Access Network Architecture") on a nextgeneration FTTH network, and has participated in the European projects ACCORDANCE, EUROFOS, BONE, EPHOTON/ONE/One, LION, MEPHISTO, MOON, SONATA and RACE1027, on optical transport and access networks. In 1998 he was a guest scientist in the University College of London, and he has been sub-director of the ETSETB Telecom School (UPC); he has published more than 100 international papers and edited the books "Fiber-to-theHome Technologies" and "Next-Generation FTTH Passive Optical Networks" (Springer Ed.). He is the leader of one of the "top-10" laboratories in "Fiber-tothe-Home" networks. Currently he is Associate Editor of IEEE-PTL, and TPC member of OFC. 